\title{
Penerapan Pewarnaan Graf Terhadap Penyusunan Jadwal Seminar Proposal Skripsi di Prodi Pendidikan Matematika UIN Raden Intan Lampung
}

\author{
Novian Riskiana Dewi \\ Pendidikan Matematika, UIN Raden Intan Lampung, Bandar Lampung, Indonesia; \\ novianriskiana@radenintan.ac.id
}

\begin{abstract}
Abstrak. Program Studi Pendidikan Matematika UIN Raden Intan Lampung memiliki masalah dalam proses penyusunan jadwal seminar proposal skripsi, karena banyaknya mahasiswa yang melaksanakan seminar dalam jangka waktu berdekatan. Selama ini penyusunan jadwal seminar proposal dilakukan secara manual, tak jarang banyak jadwal dosen pembimbing dan dosen penguji yang bentrok dengan jadwal seminar proposal mahasiswa yang lain. Untuk mengatasi permasalahan tersebut, maka disusunlah jadwal seminar proposal skripsi dengan menerapkan konsep pewarnaan titik pada graf menggunakan Algoritma Welch Powell. Titik-titik pada graf direpresentasikan sebagai mahasiwa yang akan melaksanakan seminar proposal skripsi, sedangkan sisi yang menghubungkan dua titik menyatakan dua titik tersebut memiliki satu dan/atau dua dosen pembimbing yang sama. Metode penelitian yang digunakan adalah metode penelitian studi literatur. Hasil dari penelitian ini menunjukkan bahwa pewarnaan graf dengan algoritma Welch Powell dapat diterapkan untuk menyusun jadwal seminar proposal skripsi mahasiswa Program Studi Pendidikan Matematika, Fakultas Tarbiyah dan Keguruan UIN Raden Intan Lampung.
\end{abstract}

Kata Kunci: pewarnaan graf, penyusunan jadwal,algoritma welch powell

Abstract. Mathematics Education of UIN Raden Intan Lampung has a problem in the process of preparing the thesis proposal seminar schedule, because there are many students who conduct seminars in the adjacent period. During this time the preparation of the proposal seminar schedule is done manually, not infrequently many schedule lecturers and examiners are clashing with other student proposal seminar schedules. To overcome these problems, a thesis proposal seminar schedule was arranged by applying the concept of point coloring to graphs using the Welch Powell Algorithm. The points on the graph are represented as students who will conduct a thesis proposal seminar, while the side that connects the two points states that these two points have one and / or two supervisors. The research method used is the study method of literature study. The results of this study indicate that graph coloring using Welch Powell algorithm can be applied to arrange seminar schedule for students' thesis proposal for Mathematics Education, Faculty of Tarbiyah and Teacher Training. UIN Raden Intan Lampung.

Keywords: coloring graph, scheduling, algoritma welch-powell 


\section{Pendahuluan}

Skripsi merupakan syarat kelulusan bagi setiap mahasiswa. Sebelum menyelesaikan skripsi tentunya harus melalui tahapan seminar proposal skripsi terlebih dahulu. Penyusunan jadwal seminar proposal skripsi ini membawa masalah tersendiri bagi mahasiwa dan dosen di Program Studi Pendidikan Matematika UIN Raden Intan Lampung. Proses penyusunan jadwal seminar proposal skripsi yang masih dilakukan secara manual membutuhkan ketelitian yang tinggi agar tidak ada jadwal dosen yang bentrok dengan jadwal yang lain. Banyaknya mahasiswa yang mendaftar seminar proposal di periode waktu yang sama dan satu dan/atau dua dosen pembimbing yang sama membutuhkan ketelitian untuk menentukan jadwal seminar proposal dan penentuan dosen penguji, ketua dan sekretaris.

Permasalahan penyusunan jadwal seminar proposal skripsi ini membutuhkan suatu alternatif teknik yang lebih efektif dibandingan dengan penyusunan jadwal secara manual. Salah satu cara yang dapat diterapkan yaitu pewarnaan graf dengan menggunakan Algoritma Welch-Powell.

Pewarnaan graf terbagi menjadi 3, yaitu pewarnaan titik, pewarnaan sisi, dan pewarnaan wilayah. Seperti pada penelitian (Bustan \& Salim, Juli 2019) memberikan kesimpulan bahwa pewarnaan titik menggunakan Algoritma Welch-Powell dapat digunakan dalam menentukan jadwal bimbingan mahasiswa agar tidak bentrok dengan mahasiswa yang lain dan tidak mengantri lama untuk bisa bimbingan dengan dosennya. Selain itu hasil penelitian (Mahmudah \& Irawati, 2018) menyimpulkan bahwa teknik pewarnaan simpul graf dapat diterapkan untuk membentuk jadwal ujian semester. Peneliti tertarik untuk menerapkan pewarnaan graf terhadap penyusunan jadwal seminar proposal skripsi di Prodi Pendidikan Matematika UIN Raden Intan Lampung.

Pewarnaan Titik pada Graf

Pewarnaan pada graf terbagi menjadi tiga, yaitu pewarnaan titik (vertex coloring), pewarnaan sisi (edge coloring), dan pewarnaan wilayah. Pewarnaan titik yaitu memberikan warna yang berbeda pada setiap titik yang bertetangga, sehingga tidak ada dua titik yang bertetangga dengan warna yang sama. Pewarnaan sisi yaitu memberikan warna yang berbeda pada setiap sisi yang bertetangga, sehingga tidak ada dua sisi yang bertetangga dengan warna yang sama. Sedangkan pewarnaan wilayah yaitu memberikan

Copyright $(02020$

\section{Buana Matematika :}

Jurnal Ilmiah Matematika dan Pendidikan Matematika 
warna yang berbeda pada setiap wilayah atau daerah yang bertetangga, sehingga tidak ada dua wilayah yang bertetangga dengan warna yang sama.

\section{Algoritma Welch-Powell}

Langkah-langkah pada Algoritma Welch-Powell sebagai berikut :

1. Titik pada graf diurutkan dari derajat yang tertinggi.

2. Titik yang mempunyai derajat tertinggi diberikan sebuah warna.

3. Semua titik yang tidak bertetangga dengan titik berderajat tertinggi diberikan warna yang sama.

4. Ulangi lagi langkah 2 dan 3 untuk titik yang berderajat tinggi kedua sampai semua titik telah diberikan warna.

\section{Metode}

Metode penelitian yang digunakan pada penelitian ini adalah :

1. Studi literatur

Peneliti mengumpulkan referensi dari buku dan jurnal yang berkaitan dengan metode pewarnaan graf.

2. Pengumpulan data

Peneliti mengumpulkan data mahasiswa dan dosen pembimbing yang akan melaksanakan seminar proposal skripsi.

3. Pelaksanaan penelitian

Menentukan titik-titik yang merepresentasikan mahasiswa dengan melabeli berdasarkan inisial nama, kemudian dilakukan pewarnaan titik menggunakan Algoritma Welch-Powell, menentukan nama dosen penguji, ketua dan sekretaris. Setelah itu didapatkan kesimpulan jadwal seminar proposal skripsi.

\section{Hasil dan Pembahasan}

Penelitian ini dimulai dari mengumpulkan referensi buku dan jurnal yang berkaitan dengan metode pewarnaan graf menggunakan Algoritma WelchPowell. Kemudian mengumpulkan data mahasiswa dan dosen pembimbing yang akan melaksanakan seminar proposal skripsi. Data yang diperoleh ada 16 mahasiswa dan 13 dosen pembimbing. Selanjutnya nama mahasiswa dituliskan dengan inisial kemudian direpresentasikan sebagai titik. Sedangkan sisi yang menghubungkan dua titik menyatakan ada satu dan/atau dua dosen pembimbing yang sama. Berikut daftar nama mahasiswa dan dosen pembimbing. 
Tabel 1. Daftar Nama Mahasiswa dan Dosen Pembimbing

\begin{tabular}{clll}
\hline No & \multicolumn{1}{c}{ Nama Mahasiswa } & \multicolumn{1}{c}{ Dosen Pemimbing I } & \multicolumn{1}{c}{ Dosen Pemimbing II } \\
\hline 1. & Fitria Adelita (FA) & Dr. Achi Rinaldi, M. Si & Fredi Ganda Putra, M. Pd \\
2. & Damayanti (D) & Dr. Rubhan Masykur, M. Pd & Dona Dinda, M. Pd \\
3. & Yuliana (Y) & Netriwati, M. Pd & Siska Andriani, M. Pd \\
4. & Vivi Irfana Safitri (VIS) & Dr. Nanang Supriadi, M. Sc & Fredi Ganda Putra, M. Pd \\
5. & Siti Nuraini (SN) & Dr. Bambang Sri A, M. Pd & Abi Fadila, M. Pd \\
6. & Shafira Syahnaz (SS) & Dr. Nanang Supriadi, M. Sc & Fredi Ganda Putra, M. Pd \\
7. & Nuaf Wiranti (NW) & Dr. Achi Rinaldi, M. Si & Dona Dinda, M. Pd \\
8. & Inne Dwi Utari (IDU) & Farida, MMSI & Komarudin, M. Pd \\
9. & Ladika Anathiya (LA) & Netriwati, M. Pd & Siska Andriani, M. Pd \\
10. & Misna Hasana (MH) & Dr. Rubhan Masykur, M. Pd & Dona Dinda, M. Pd \\
11. & Nuryati (N) & Dr. Bambang Sri A, M. Pd & Rizki Wahyu, M. Pd \\
12. & Anggara Yugo (AY) & Farida, MMSI & Rizki Wahyu, M. Pd \\
13. & Kiki Ambar Sari (KAS) & Dr. Achi Rinaldi, M. Si & Siska Andriani, M. Pd \\
14. & Riski Susanti (RS) & Dr. Nanang Supriadi, M. Sc & Rizki Wahyu, M. Pd \\
15. & Endang Putri (EP) & Mujib, M. Pd & Rizki Wahyu, M. Pd \\
16. & Astika Dwi (AD) & Mujib, M. Pd & Siska Andriani, M. Pd \\
\hline
\end{tabular}

Daftar nama mahasiwa tersebut dituliskan dengan inisial nama untuk mempermudah, kemudian digambarkan menjadi sebuah graf yang dihubungkan sisi-sisinya berdasarkan mahasiswa yang memiliki satu dan/atau dua pembimbing yang sama akan dihubungan dengan garis.

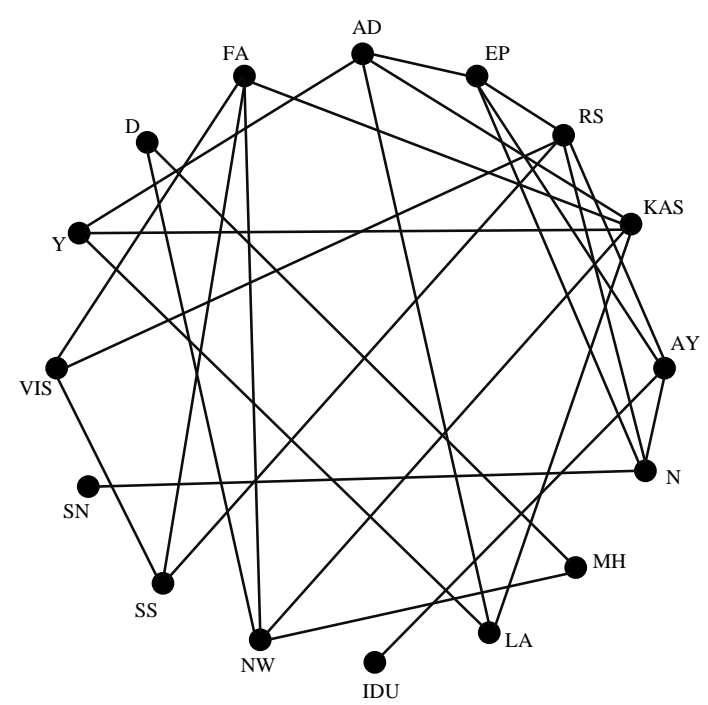

Gambar 1. Representasi Nama Mahasiswa

Berdasarkan Gambar 1 dapat dilihat bahwa titik-titik saling berhubungan dan bertetangga, bahkan satu titik dapat terhubung dengan lima titik yang Copyright $\odot 2020$

\section{Buana Matematika :}

Jurnal Ilmiah Matematika dan Pendidikan Matematika 
berbeda. Berikut titik yang bertetangga dan derajat tiap titiknya disajikan dalam bentuk tabel agar lebih mudah untuk melihatnya. Dari Tabel 2 diperoleh derajat tertinggi adalah 5 yaitu pada titik KAS dan RS.

Tabel 2. Daftar Nama Mahasiswa dan Dosen Pembimbing

\begin{tabular}{clc}
\hline Titik & \multicolumn{1}{c}{ Titik yang Bertetangga } & Derajat Titik \\
\hline FA & VIS, SS, NW, KAS & 4 \\
D & MH, NW & 2 \\
Y & AD, KAS, LA & 3 \\
VIS & SS, RS, FA & 3 \\
SN & N & 1 \\
SS & VIS, RS, FA & 3 \\
NW & FA, KAS, D, MH & 4 \\
IDU & AY & 1 \\
LA & Y, KAS, AD & 3 \\
MH & D, NW & 2 \\
N & SN, AY, RS, EP & 4 \\
AY & IDU, N, RS, EP & 4 \\
KAS & FA, NW, Y, LA, AD & 5 \\
RS & VIS, SS, N, AY, EP & 5 \\
EP & AD, N, AY, RS & 4 \\
AD & EP, Y, LA, KAS & 4 \\
\hline
\end{tabular}

Langkah pertama warnai titik yang memiliki derajat tertinggi. Pada graf tersebut derajat tertinggi ada 2 titik yaitu titik KAS dan RS sama-sama memiliki derajat 5. Misalkan kita memilih titik KAS dengan memberi warna merah. Selanjutnya warnai semua titik yang tidak berhubungan dengan titik KAS menggunakan warna merah.

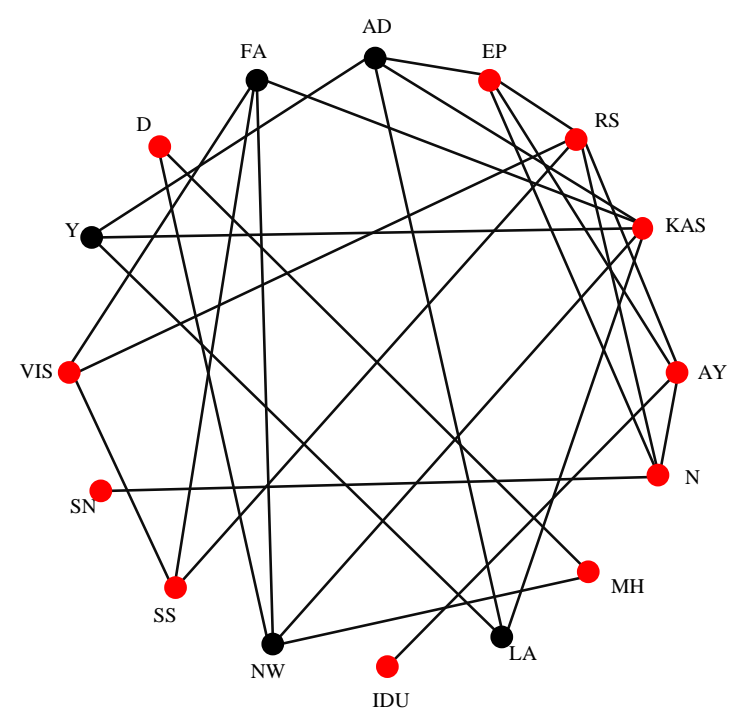

Gambar 2. Pemberian Warna Pertama

Copyright (C) 2020

Buana Matematika :

Jurnal Ilmiah Matematika dan Pendidikan Matematika 
Setelah titik KAS dan titik-titik yang tidak berhubungan dengan titik KAS diwarnai dengan warna merah yaitu 11 titik, terdapat beberapa titik yang bertetangga memiliki warna yang sama. Sedangkan titik yang bertetangga tidak boleh diwarnai yang sama yaitu warna merah, ada 6 titik yang harus diganti warnanya yaitu titik RS, SN, SS, MH, N, AY.

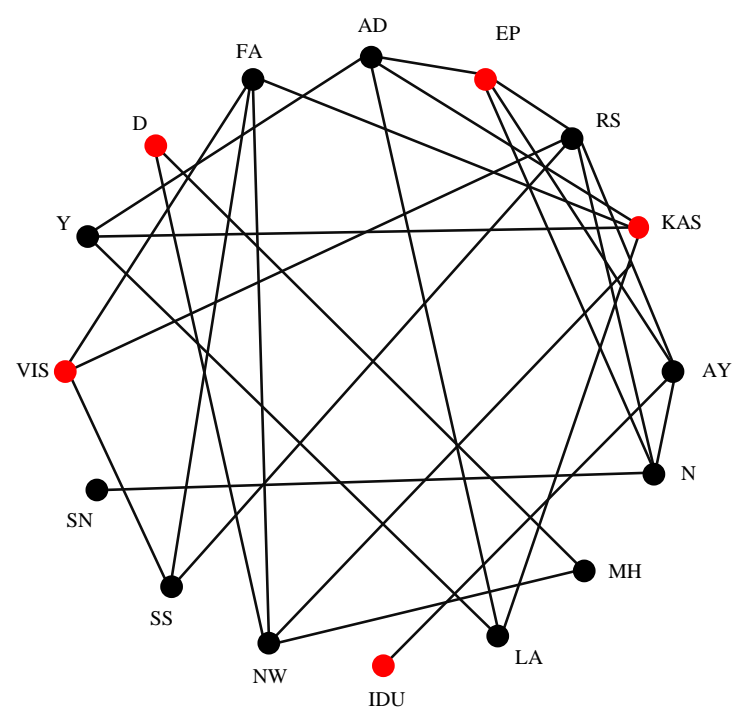

Gambar 3. Menghilangkan Warna Merah yang Bertetangga

Setelah menghilangkan warna merah pada titik RS, SN, SS, MH, N, dan AY. Selanjutnya dengan cara yang sama warnai titik yang berderajat tertinggi yang lain yaitu titik RS dan titik-titik yang tidak berhubungan dengan titik RS dengan warna kuning. Sedangkan titik yang bertetangga tidak boleh memiliki warna yang sama.

\section{Buana Matematika :}

Jurnal Ilmiah Matematika dan Pendidikan Matematika 


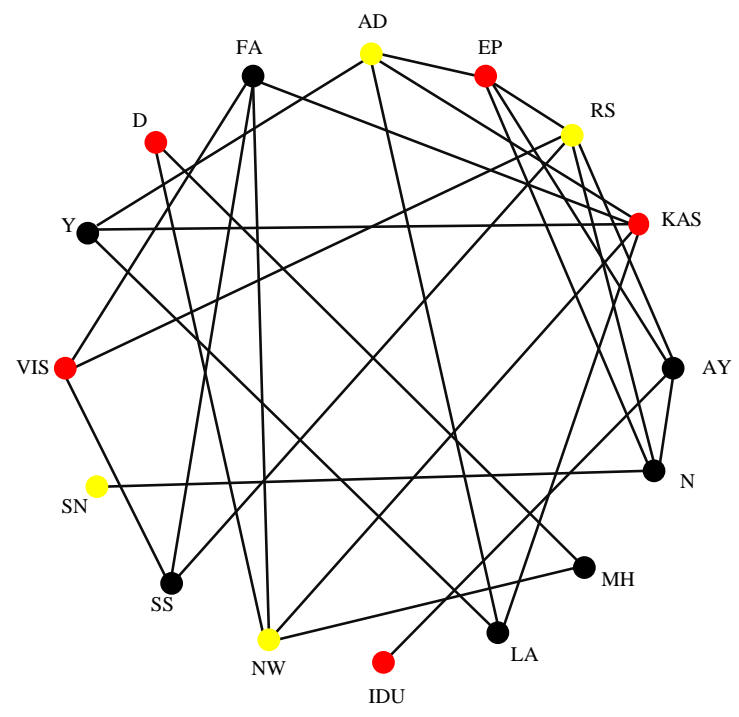

Gambar 4. Pemberian Warna Kuning

Ada 4 titik yang diwarnai dengan warna kuning, yaitu titik RS, AD, SN, dan NW. Selanjutnya lakukan dengan cara yang sama pada titik lainnya sedemikian sehingga semua titik diberi warna dan tidak ada titik yang bertetangga memiliki warna yang sama.

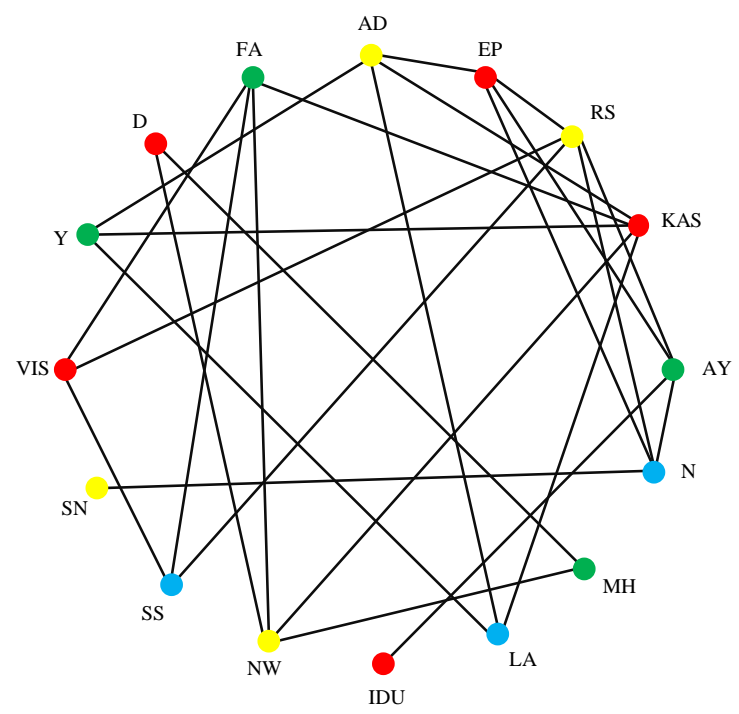

Gambar 5. Hasil Pewarnaan Semua Titik

Setelah semua titik diberikan warna dan titik yang bertetangga tidak memiliki warna yang sama, maka diperoleh 4 warna yaitu merah, kuning, hijau, dan biru. Berikut adalah hasil pewarnaannya :

Titik warna merah : D, VIS, IDU, KAS, EP

Titik warna kuning : AD, SN, NW, RS

Titik warna hijau : FA, Y, MH, AY

Copyright (C) 2020

\section{Buana Matematika :}

Jurnal Ilmiah Matematika dan Pendidikan Matematika 
Titik warna biru : SS, LA, N

Berdasarkan pewarnaan dengan menggunakan Algoritma Welch-Powell diperoleh empat warna yang menunjukkan empat waktu jadwal seminar yang nantinya akan digabungkan dengan nama dosen ketua, penguji, dan sekretaris. Daftar nama dosen yang menjadi ketua, dosen penguji, dan sekretaris saat seminar proposal skripsi sebagai berikut :

Tabel 3. Daftar Nama Dosen Ketua, Penguji, dan Sekretaris

\begin{tabular}{llll}
\hline No & \multicolumn{1}{c}{ Ketua } & \multicolumn{1}{c}{ Penguji } & \multicolumn{1}{c}{ Sekretaris } \\
\hline 1. & Dr. Bambang Sri A, M. Pd & Netriwati, M. Pd & Abi Fadila, M. Pd \\
2. & Dr. Rubhan Masykur, M. Pd & Fredi Ganda Putra, M. Pd & Komarudin, M. Pd \\
3. & Dr. Nanang Supriadi, M. Sc & Mujib, M. Pd & Novian Riskiana, M. Si \\
4. & Dr. Achi Rinaldi, M. Si & Farida, MMSI & Dona Dinda, M. Pd \\
\hline
\end{tabular}

Hasil pewarnaan titik ada 4 warna yaitu merah, kuning, hijau, dan biru kemudian tiap warna tersebut akan digabungkan dengan nama dosen ketua, penguji, dan sekretaris yang akan bertugas pada seminar proposal skripsi.

Berikut jadwal seminar proposal skripsi yang diperoleh:

1. Titik warna merah akan disandingkan dengan dosen Dr. Bambang Sri A, M. Pd sebagai ketua, Netriwati, M. Pd sebagai penguji, dan Abi Fadila, M. Pd sebagai sekretaris.

2. Titik warna kuning akan disandingkan dengan dosen Dr. Rubhan Masykur, M. Pd sebagai ketua, Fredi Ganda Putra, M. Pd sebagai penguji, dan Komarudin, M. Pd sebagai sekretaris.

3. Titik warna hijau akan disandingkan dengan dosen Dr. Nanang Supriadi, M. Sc sebagai ketua, Mujib, M. Pd sebagai penguji, dan Novian Riskiana, M. Si sebagai sekretaris.

Titik warna biru akan disandingkan dengan dosen Dr. Achi Rinaldi, M. Si sebagai ketua, Farida, MMSI sebagai penguji, dan Dona Dinda, M. Pd sebagai sekretaris.

\section{Simpulan}

Berdasarkan hasil penerapan pewarnaan graf yang telah dilakukan diperoleh kesimpulan bahwa pewarnaan graf pada titik dengan menggunakan Algoritma Welch-Powell dapat diterapkan untuk menyusun jadwal seminar proposal skripsi di Prodi Pendidikan Matematika UIN Raden Intan Lampung.

Copyright $@ 2020$

Buana Matematika :

Jurnal Ilmiah Matematika dan Pendidikan Matematika 
Sehingga jadwal yang disusun tidak bentrok dengan jadwal seminar yang lain dengan dosen pembimbing yang sama.

Berdasarkan hasil penelitian ini penulis memberikan saran untuk menggunakan pewarnaan graf saat menyusun jadwal seminar proposal skripsi. Program penelitian ini dapat ditingkatkan lagi dalam hal ketepatan jadwal dan bisa menambahkan variabel-variabel lain seperti ruang seminar yang tersedia dan jadwal mengajar dosen dimasukkan juga dalam program tersebut.

\section{Ucapan Terima Kasih}

Peneliti menyampaikan terima kasih kepada beberapa pihak yang membantu dalam menyelesaikan penelitian ini, yaitu kaprodi dan dosen yang bertugas sebagai penerima pendaftaran seminar proposal yang telah membantu memberikan informasi berupa data mahasiswa dan dosen pembimbing.

\section{Daftar Pustaka}

Bustan, A. W., \& Salim, M. R. (Juli 2019). Penerapan Pewarnaan Graf Menggunakan Algoritma Welch-Powell untuk Menentukan Jadwal Bimbingan Mahasiswa. THEOREMS (The Original Research of Mathematics) Vol. 4 No. 1, 79-86.

Hartsfield, N., \& Ringel, G. (1990). Pearls in Graph Theory. London: Academic Press.

Mahmudah, M., \& Irawati, T. N. (2018). Aplikasi Pewarnaan Garf Terhadap Pembuatan Jadwal Ujian Semester di Jurusan Pendidikan Matematika Universitas Islam Jember. Kadikma, Vol. 9, No. 2, 12-21.

\section{Riwayat Hidup Penulis}

\section{Novian Riskiana Dewi}

Lahir di Banyuwangi, 24 November 1990. Staf pengajar di
Universitas Islam Negeri Raden Intan Lampung. Studi S1
Pendidikan Matematika di Universitas Jember, Jember, lulus
tahun 2013, dengan tema skripsi teori graf; S2 Matematika,
Institut Teknologi Sepuluh Nopember, Surabaya, lulus tahun
2015 dengan tema tesis teori graf.


Jurnal Ilmiah Matematika dan Pendidikan Matematika Vol. 10 No. 1 (2020)

Halaman ini sengaja dikosongkan

Copyright $@ 2020$

Buana Matematika :

Jurnal Ilmiah Matematika dan Pendidikan Matematika

p-ISSN : 2088-3021 e-ISSN : 2598-8077 